\title{
Effect of different herbal preparations on experimental viral respiratory complex of broilers: clinical, pathological and ciliary activity aspects
}

\author{
Mohammad Abbasnia $^{1^{\circledR}}$, Najmeh Mosleh $^{1^{*}}$, Habbibollah Dadras $^{1^{\circledR}}$, Ghasem Rezaeianzadeh $^{{ }^{\circledR}}$, Zahra \\ Boroomand $^{3}$ \\ ${ }^{1}$ Department of Clinical Sciences, School of Veterinary Medicine, Shiraz University, Shiraz, Iran \\ ${ }^{2}$ Iran Veterinary Organization, Tehran, Iran \\ ${ }^{3}$ Department of Clinical Sciences, Faculty of Veterinary Medicine, Shahid Chamran University of Ahvaz, Iran
}

\section{A R T I C L E I N F O}

Article Type:

Original Article

\section{Article History:}

Received: 8 November 2019

Accepted: 21 January 2020

\section{Keywords:}

Avian influenza

Infectious bronchitis

Plant preparations

Chickens

\begin{abstract}
A B S T R A C T
Introduction: Despite the extensive use of herbal preparations for treatment of viral respiratory diseases in poultry, few studies have analyzed the effectiveness of these products. This study aimed to evaluate the effects of three different herbal respiratory symptom relieving agents in broiler chickens experimentally infected with H9N2 avian influenza (AI) and infectious bronchitis (IB) viruses.

Methods: A total of 175 broiler chickens were randomly assigned into 5 equal groups. Negative control (NC) group remained intact while others received H9N2-AI and IB viruses. Treatment groups (G1-G3) but not positive control (PC) birds were treated with three different herbal agents containing menthol. Clinical and pathological aspects were evaluated during the experiment.

Results: Administration of these agents to challenged chickens not only did not notably decrease clinical severity, gross and histopathological lesions, but also markedly increased mortality rate in treated groups. In dead cases, cast/plug formation was a prominent feature in the trachea. Treatment with herbal agents induced an increase of more than twofold in the number of goblet cells compared to PC group. Significant ciliostasis was observed in all challenged groups regardless of treatment, while ciliary activity was not changed statistically in comparison with the mean values of PC.

Conclusion: In this study administration of herbal preparations adversely affected the tracheal epithelium via enhancement of goblet cell hyperplasia. It appears that hyper-secretion of mucosa along with ciliary incompetence causes mucus stagnation followed by tracheal or bronchial obstruction and death. These findings necessitate cautious use of these products.
\end{abstract}

Implication for health policy/practice/research/medical education:

The outcome of the study may be helpful for increasing veterinarians' knowledge to choose proper therapeutic agents in confronting broiler respiratory viral complex.

Please cite this paper as: Abbasnia M, Mosleh N. Dadras H., Rezaeinzadeh Gh. Boroomand Z. Effect of different herbal preparations on experimental viral respiratory complex of broilers: clinical, pathological and ciliary activity aspects. J Herbmed Pharmacol. 2020;9(3):277-285. doi: 10.34172/jhp.2020.35.

\section{Introduction}

Viral diseases of respiratory tract affect commercial poultry farms worldwide. Low pathogenic avian influenza viruses (AIVs) such as H9N2 have become enzootic in poultry in many Middle Eastern countries. Despite long-term vaccination programs against H9N2 in some countries, economic losses due to this virus in poultry industry are noticeable and should be considered as a continuous threat (1). The H9N2 virus has the potential to cause severe respiratory disease in combination with other viruses or bacteria including the Newcastle disease virus, infectious bronchitis virus (IBV) and Mycoplasma gallisepticum (MG) (2). The avian infectious bronchitis (IB) virus continues to be one of the most economically 
damaging diseases in chickens despite intensive control (3). High prevalence of mixed infections of AIV-H9N2 and IBV has been reported in field studies $(4,5)$ which shows a potential role of IBV or even IB live vaccines in exacerbating the clinical manifestation of H9N2 infection in broilers (6).

There are no specific treatments for viral diseases and antiviral drugs are not ordinarily used in poultry industry. Antibacterial drugs may be used to prevent and treat secondary bacterial infections. On the other hand, there are a number of commercially available herbal preparations which are used in many countries as symptom relieving agents in respiratory tract infections. However, rational recommendation of these drugs for management of respiratory diseases in poultry is controversial due to lack of information from well-designed experimental trials.

Essential oils have long been recognized for their antibacterial, antifungal, antiviral, insecticidal and antioxidant properties (7-9). The chemical composition and concentration of essential oils are variable. Essential oils are generally used as blend with a carrier oil or in combination with other plant oils in the feed to enhance the productive performance of birds (10). In the majority of circumstances most of the commercial medicines are made by mixing three or more types of essential oils. Few studies have evaluated the use of essential oils in respiratory diseases of chickens. Barbour et al demonstrated that Mentofin ${ }^{\circledR}$ (a herbal product containing $10 \%$ eucalyptus oil, $10 \%$ menthol, $33 \%$ liquid builders and $47 \%$ saponins) had a healing effect against MG/H9N2 infection in broilers $(11,12)$. It has been shown that Zataria multiflora essential oil has a positive effect on reducing H9N2 AIV replication, decreasing clinical signs and improving the performance in broilers (13). In a research study by Rehman et al, Mentofin ${ }^{\circledR}$ treated chickens showed higher antibody titer against ND virus vaccine as compared to untreated groups (14). Effect of Mentofin ${ }^{\circledR}$ on MG clearance from the tracheal epithelium has also been shown by Kahaya et al (15). Moreover, the positive effects of volatile oils administrations on immune response of birds to vaccines have been reported (16-18).

Menthol, a monoterpenoid synthesized by plants from Mentha genus (19), and mentol containing agents as well as mucoactive drugs such as bromhexine, which is a derivate of the Adhatoda vasica plant industry (20), are widely used to alleviate bronchitis or as a therapeutic option for mucus alterations, including hypersecretion in the treatment of respiratory diseases of poultry.

On the contrary, there are frequent oral claims from clinicians that treatment of viral respiratory diseases in broiler chickens which is carried out mostly through the administration of respiratory symptom relieving agents, not only doesn't have any positive effects on mortality rate but also may deteriorate the condition. Moreover, treatment with these agents is linked to significant expenses. In fact, knowledge on the effectiveness of these therapeutic modalities is scarce. The mechanism of action of these drugs is also unknown in birds. Thus, in an attempt to further investigate the outcome of using three available respiratory symptom relieving compounds including Mentofin $^{\circledR}$, $\operatorname{Aromax}^{\circledR}$ and Kimia Mentholhexine ${ }^{\circledR}$ in an experimental complex respiratory disease $(\mathrm{H} 9 \mathrm{~N} 2+\mathrm{IB})$ in broiler chickens, this study was performed. The study was based on clinical, histopathological and ciliary activity evaluations.

\section{Materials and Methods}

\section{Challenge viruses}

H9N2 AIV subtype (A/chicken/Iran/772/1998/H9N2) and variant IBV isolate (793/B serotype IBFIBV32) were used as challenge viruses in the present study. Each viral stock was propagated separately by injecting the allantoic cavity of 9-day-old embryonated chicken eggs and subsequently titrated according to the Reed and Muench method, to determine $50 \%$ embryo infectious dose $\left(\mathrm{EID}_{50}\right)$ (21). H9N2 virus was used in a dose of $10^{7.1}$ EID50/bird ( $50 \mu \mathrm{L}$ intranasally by nasal instillation and $50 \mu \mathrm{L}$ through eye drop) and IBV virus in a dose of $10^{5}$ EID50/bird IBV $(50 \mu \mathrm{L}$ intranasally by nasal instillation and $50 \mu \mathrm{L}$ through eye drop).

\section{Chickens}

A total of 175 one-day-old commercial broiler chickens (Hubbard) were purchased and used for this experiment. The birds were randomly divided into different groups. To prevent cross-contamination throughout the course of the experiment, each group was housed in an isolated room under strict biosecurity conditions. All chicks in this experiments were not vaccinated. Birds had free access to feed and water. Diet formulation and environmental factors were adjusted in accordance with the Hubbard company rearing manual. This study was carried out in accordance with ethical guidelines of the Institutional Animal Care and Use Committee, which set by the European convention (No. 123).

\section{Experimental design}

In this experiment, broiler chickens (described above) were assigned at random into 5 groups ( 35 birds/group). Two groups of birds were not treated and one group was served as challenged group (positive control: PC; $\mathrm{n}=35$ ) and another group was assigned as non-challenged negative control (NC; $n=35)$. At 25 days of age, the birds in PC and treatment groups (G1-G3) were challenged. To ensure that infection had occurred, the birds in each group were examined twice daily for clinical signs of the disease. Administration of herbal preparations into treatment groups was started after manifestation of clinical sings [from day 2 post inoculation (PI)] and continued for 5 consecutive days. The birds in treatment groups were 
treated as follows: G1) Mentofin ${ }^{\circledR}$ (10\% eucalyptus oil, $10 \%$ menthol, $33 \%$ liquid builders and $47 \%$ saponins) 200 $\mathrm{ml} / 1000 \mathrm{ml}$ drinking water ;( EWABO, Germany); G2) $\operatorname{Aromax}^{\circledR}$ (Eucalyptus oil, Mint oil, L-Menthol, Thyme oil) (XVet, Germany) $200 \mathrm{~mL} / 1000 \mathrm{ml}$ drinking water twice daily; G3) Kimia Mentholhexine ${ }^{\circledR}$ (Bromhexine 1\%+ menthol) (Kimiafaam Pharmaceutical Co. Tehran, Iran) $1 / 1000 \mathrm{v} / \mathrm{v}$ in drinking water. Dosage of each compound was based on the manufacturer's recommendations. Body weight gain and feed consumption of chickens and clinical signs of the disease were recorded daily from day 25 to the end of study period (12 days post infection).

\section{Sample collection and preparation}

On days 1, 3, 6 and 12 post challenge, five birds from each group were euthanized with intravenous injection of sodium pentobarbital $(50 \mathrm{mg} / \mathrm{kg})$ and necropsied immediately. Gross lesions were recorded and the samples of each bird (5 birds) were collected for histopathological and ciliostasis evaluation at days 1, 3 and 6 post inoculation as follows: Tracheal (lower part, near to tracheal bifurcation) samples were collected in $10 \%$ neutral buffered formalin and after dehydration, embedded in paraffin. Serial sections $(5-\mu \mathrm{m})$ were cut for hematoxylin and eosin ( $\mathrm{H} \& \mathrm{E})$ as well as periodic acidSchiff (PAS) staining. Three slides were prepared from each sample of each bird for each H\&E and PAS staining. Each slide contained 3 sections cut. In addition, tracheal sections from upper, middle and lower parts of trachea were also harvested from each of scarified birds per group at days 1, 3 and 6 post challenge for ciliostasis assays.

\section{Determination of clinical severity}

To evaluate severity, clinical scoring was used. Clinical signs were scored as described previously by Jackwood et al (1: normal; 2: watery eyes or mucus in the nares; 3 : watery eyes and mucus in the nares; 4 : watery eyes, mucus in nares and tracheal rales) (22).

Lesions of the tracheas, lungs and air sacs were scored for gross severity in 5 birds of each group. The gross lesions in trachea (mucin exudates and cast), syrinx (tubular cast), air sacs (airsacculitis) and lung (congestion and bronchial cast) were scored. Briefly, respiratory organs were scored altogether on scale of 1 to 4 , as 1: no lesions, 2: mild or slight lesions, 3: moderate lesions, and 4: severe lesions. Dead birds in each group were also necropsied and qualitatively evaluated.

\section{Histopathological evaluation}

The histological findings were graded on a scale of 1 (normal) to 4 (severe) (22) in 5 randomly selected microscopic field of each tracheal section for the following variables: epithelial hyperplasia, lymphocyte infiltration and the epithelial deciliation. The number of goblet cells in the epithelium of trachea was counted in 5 microscopic field in each of the PAS stained sections. These values were then averaged.

\section{Ciliostasis assay}

In order to remove mucin from the tracheal epithelial surface, tracheal samples were placed in Hank's balanced salt solution containers. Three thin rings from the upper and lower parts of the trachea and four from the middle part were prepared by surgical blade. The rings were placed separately in tissue culture micro plates containing Dulbecco's modified eagle medium and were shaken gently at $37^{\circ} \mathrm{C}$ for few minutes. The ciliary movement was then assessed microscopically and scored on scale from 0 (100\% ciliary activity) to 4 (total ciliostasis) (23). These scores were then averaged to give a final score.

Data analysis

Statistical analysis was performed using SPSS software version 22. All data were expressed as the mean \pm standard deviation (SD) and analyzed by parametric or nonparametric statistics including one-way ANOVA followed by Tukey's multiple comparison, MannWhitney $U$ test and Kruskal-Wallis one-way analysis of variance where appropriate. For all cases differences were considered significant at $P<0.05$

\section{Results}

Clinical severity evaluations

All of the birds in negative control group were scored as normal for clinical signs, gross and histopathological parameters through the experiment and no mortality was observed in this group.

Mild respiratory signs including watery eyes or mucosa in nares were observed in most of the birds in challenged groups regardless of treatment which appeared from day 2 PI. Respiratory signs were observed from day 3 to day 9 PI including nasal discharge, rales and excessive lacrimation with the most severe signs appeared on day 6 PI. Table 1 shows that clinical signs scores for the treated and challenged groups were statistically higher than NC group while no significant differences were observed between PC and treated groups at days 1, 3, 6 and 9 PI. In addition, clinical scores were statistically the same among treated groups on these days. On day 12 post challenge, no differences were observed among birds alive in NC, PC and all treated groups.

Mortality rate in PC group was $8.6 \%$ while G3 (bromhexine $1 \%+$ menthol treated) group appeared to have the highest mortality rate $(28.6 \%)$ followed by G1 (Mentofin ${ }^{\circledR}$ treated group; 25.7\%) and G2 (Aromax ${ }^{\circledR}$; $22.8 \%$ ) groups (Table 1). In PC and treatment groups death was initiated from day 4 and peaked during day 6 to 8 PI. Death occurred until day 9 in G3 and G1 groups. No differences were observed in body weight among groups at the end of the experiment (Table 1). All challenged 
Table 1. Body weight, FCR, scores of clinical signs and mortality rate in different groups

\begin{tabular}{|c|c|c|c|c|c|c|c|c|}
\hline \multirow{2}{*}{ Groups } & \multicolumn{5}{|c|}{ Clinical signs severity (Mean \pm SD) ${ }^{*}$} & \multirow{2}{*}{$\begin{array}{l}\text { Mortality } \\
\text { No. (\%) }\end{array}$} & \multirow{2}{*}{$\begin{array}{l}\text { Body weight (g) } \\
\text { (Mean } \pm S D)\end{array}$} & \multirow{2}{*}{ FCR } \\
\hline & 1 & 3 & 6 & 9 & 12 & & & \\
\hline NC & $1 \pm 0^{\mathrm{a}}$ & $1 \pm 0^{\mathrm{a}}$ & $1 \pm 0^{\text {a }}$ & $1 \pm 0^{\text {a }}$ & $1 \pm 0^{\text {a }}$ & 0 & $2240 \pm 31^{a}$ & 1.98 \\
\hline PC & $1.4 \pm 0.52^{\mathrm{a}}$ & $2.7 \pm 0.67^{b}$ & $3.2 \pm 0.42^{\mathrm{b}}$ & $2.8 \pm 0.79^{b}$ & $2 \pm 0.67^{a}$ & $3(8.6)$ & $2111 \pm 118^{a}$ & 2.18 \\
\hline G1 & $1.4 \pm 0.52^{\mathrm{a}}$ & $2.6 \pm 0.69^{b}$ & $3.5 \pm 0.71^{b}$ & $3.1 \pm 0.73^{b}$ & $2.1 \pm 0.74^{\mathrm{a}}$ & $9(25.7)$ & $2125 \pm 92^{\mathrm{a}}$ & 2.17 \\
\hline G2 & $1.4 \pm 0.52^{\mathrm{a}}$ & $2.8 \pm 0.42^{b}$ & $3.6 \pm 0.69^{b}$ & $3.2 \pm 0.79^{b}$ & $2.1 \pm 0.92^{\mathrm{a}}$ & $8(22.8)$ & $2111 \pm 95^{\mathrm{a}}$ & 2.17 \\
\hline G3 & $1.4 \pm 0.52^{\mathrm{a}}$ & $2.7 \pm 0.82^{b}$ & $3.6 \pm 0.69^{b}$ & $3 \pm 0.94^{\mathrm{b}}$ & $2 \pm 0.92^{\mathrm{a}}$ & $10(28.6)$ & $2060 \pm 124^{a}$ & 2.18 \\
\hline
\end{tabular}

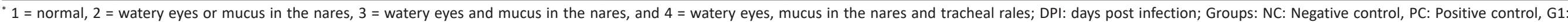
Mentofin ${ }^{\circledast}, \mathrm{G} 2$ : Aromax $^{\circledast}$ G3: Bromhexine $1 \%$ + menthol; $\mathrm{N}$ : number; FCR: feed conversion ratio.

Different superscript letter in a column indicates significant difference $(P<0.05)$.

Table 2. Scores of gross lesions (mean $\pm \mathrm{SD}$ ) in different groups

\begin{tabular}{|c|c|c|c|c|c|c|c|c|c|c|c|c|c|c|c|c|c|c|c|c|c|c|c|c|c|c|c|c|}
\hline \multirow{4}{*}{ Groups } & \multicolumn{28}{|c|}{ Scores of gross lesions (Mean \pm SD) } \\
\hline & \multicolumn{28}{|c|}{ Days post challenge } \\
\hline & \multicolumn{7}{|c|}{3} & \multicolumn{7}{|c|}{6} & \multicolumn{7}{|c|}{9} & \multicolumn{7}{|c|}{12} \\
\hline & A & B & c & D & $\mathrm{E}$ & $\mathbf{F}$ & G & A & B & c & D & $\mathrm{E}$ & $\mathbf{F}$ & G & A & B & C & D & E & $\mathbf{F}$ & G & A & B & C & D & E & $\mathbf{F}$ & G \\
\hline NC & $0^{a}$ & $0^{\mathrm{a}}$ & $0^{\mathrm{a}}$ & $0^{\mathrm{a}}$ & $0^{\mathrm{a}}$ & $0^{\mathrm{a}}$ & $0^{a}$ & $0^{\mathrm{a}}$ & $0^{\mathrm{a}}$ & $0^{\mathrm{a}}$ & $0^{\mathrm{a}}$ & $0^{a, b}$ & $0^{\mathrm{a}}$ & $0^{\mathrm{a}}$ & $0^{a}$ & $0^{\mathrm{a}}$ & $0^{\mathrm{a}}$ & $0^{\mathrm{a}}$ & $0^{a}$ & $0^{a}$ & $0^{a}$ & $0^{a}$ & $0^{\mathrm{a}}$ & $0^{\mathrm{a}}$ & $0^{\mathrm{a}}$ & $0^{a}$ & $0^{\mathrm{a}}$ & $0^{\mathrm{a}}$ \\
\hline PC & $2 \pm 0.707^{b}$ & $2^{\mathrm{b}}$ & $0^{\mathrm{a}}$ & $0^{\mathrm{a}}$ & $1 \pm 0^{\mathrm{b}}$ & $0^{\mathrm{a}}$ & $1^{a}$ & $2 \pm 1^{b}$ & $2^{\mathrm{b}}$ & $0^{\mathrm{a}}$ & $0^{\mathrm{a}}$ & $1 \pm 0.707^{a}$ & $1 \pm 0^{\mathrm{b}}$ & $2 \pm 0.707^{b}$ & $1^{a}$ & $0^{\mathrm{a}}$ & $0^{\mathrm{a}}$ & $0^{\mathrm{a}}$ & $1 \pm 0^{\mathrm{a}}$ & $1^{\text {a }}$ & $2 \pm 1.225^{\mathrm{b}}$ & $1^{a}$ & $0^{\mathrm{a}}$ & $0^{\mathrm{a}}$ & $0^{\mathrm{a}}$ & $1^{a}$ & $3 \pm 1^{b}$ & $3 \pm 1^{b}$ \\
\hline G1 & $2 \pm 1^{b}$ & $2^{\mathrm{b}}$ & $0^{\mathrm{a}}$ & $0^{\mathrm{a}}$ & $1 \pm 0.707^{\mathrm{b}}$ & $0^{\mathrm{a}}$ & $1^{\mathrm{a}}$ & $2 \pm 0.707^{b}$ & $2^{\mathrm{b}}$ & $0^{\mathrm{a}}$ & $1^{\mathrm{a}}$ & $2 \pm 0.707^{b}$ & $1^{\mathrm{b}}$ & $3 \pm 0.707^{b}$ & $1^{a}$ & $1^{a}$ & $0^{\mathrm{a}}$ & $0^{\mathrm{a}}$ & $1^{\text {a }}$ & $1^{a}$ & $3 \pm 1^{b}$ & $1^{a}$ & $1^{a}$ & $0^{a}$ & $0^{\mathrm{a}}$ & $1^{a}$ & $3 \pm 1^{b}$ & $3 \pm 1.414^{b}$ \\
\hline $\mathrm{G} 2$ & $2 \pm 0.707^{b}$ & $2^{\mathrm{b}}$ & $0^{\mathrm{a}}$ & $0^{\mathrm{a}}$ & $1 \pm 0.707^{b}$ & $0^{\mathrm{a}}$ & $1^{\mathrm{a}}$ & $2 \pm 0.707^{b}$ & $2^{b}$ & $0^{\mathrm{a}}$ & $0^{\mathrm{a}}$ & $1 \pm 0.707^{a, b}$ & $1^{\mathrm{b}}$ & $2 \pm 0.707^{b}$ & $1^{\mathrm{a}}$ & $0^{\mathrm{a}}$ & $0^{\mathrm{a}}$ & $0^{\mathrm{a}}$ & $1^{\text {a }}$ & $1^{\mathrm{a}}$ & $2 \pm 0.707^{b}$ & $1^{\mathrm{a}}$ & $1^{\mathrm{a}}$ & $0^{\mathrm{a}}$ & $0^{\mathrm{a}}$ & $0^{\mathrm{a}}$ & $3 \pm 0.707^{b}$ & $3 \pm 0.707^{b}$ \\
\hline G3 & $2 \pm 1^{b}$ & $2^{b}$ & $0^{\mathrm{a}}$ & $0^{\mathrm{a}}$ & $1^{b}$ & $0^{\mathrm{a}}$ & $1^{a}$ & $2 \pm 0.707^{b}$ & $2^{b}$ & $0^{\mathrm{a}}$ & $1^{a}$ & $2 \pm 0.707^{b}$ & $1^{\mathrm{b}}$ & $3 \pm 0.707^{b}$ & $1^{\mathrm{a}}$ & $1^{a}$ & $0^{\mathrm{a}}$ & $0^{a}$ & $1^{a}$ & $1^{a}$ & $3 \pm 0.707^{b}$ & $1^{a}$ & $1^{a}$ & $0^{\mathrm{a}}$ & $0^{a}$ & $1^{\mathrm{a}}$ & $3 \pm 1^{b}$ & $3 \pm 1^{b}$ \\
\hline
\end{tabular}

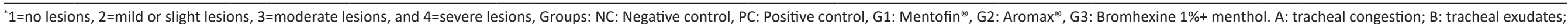
C: cast formation in trachea; D: Cast formation in tracheal bifurcation; E: lung congestion; F: pleuropneumonia; G: airsacculitis; SD: standard deviation.

Different superscript letter in a column indicates significant difference $(P<0.05)$. 
groups had higher FCR than NC group.

Gross lesions severity

Significant lesions were observed in gross pathological examination of all challenged groups compared to NC group through the experiment. Gross lesions including tracheal exudates, congestion of lung and airsacculitis were observed. Although the gross scores in all treated groups were higher than PC group throughout the experiment, the data were not statistically different. The results are shown in Table 2 .

Qualitative evaluation of gross lesions in dead birds of all treatment groups showed that all lesions were more severe in these groups than dead birds of PC group and also involved more birds. Lesions such as cast formation in trachea and syrinx (Figure 1A), tracheal congestion, tracheal exudates, airsacculitis (Figure 1B), congestion of lungs and pleuropneumonia were observed in most of the dead birds in treated groups. Cast formation in tracheal bifurcation and tracheal congestion were the most prominent lesions observed in dead birds of all groups. Tracheal cast/plug was extended to primary bronchi in some cases (data not shown).

\section{Histopathological evaluation}

The main lesions observed in challenged groups $(\mathrm{H} \&$ E staining) included loss of cilia in the epithelial cells, epithelial hyperplasia and lymphocyte infiltration into the mucosa of trachea which were mainly initiated from day 3 PI. The nature of the histological lesions and the severity and persistence of lesions did not differ among challenged

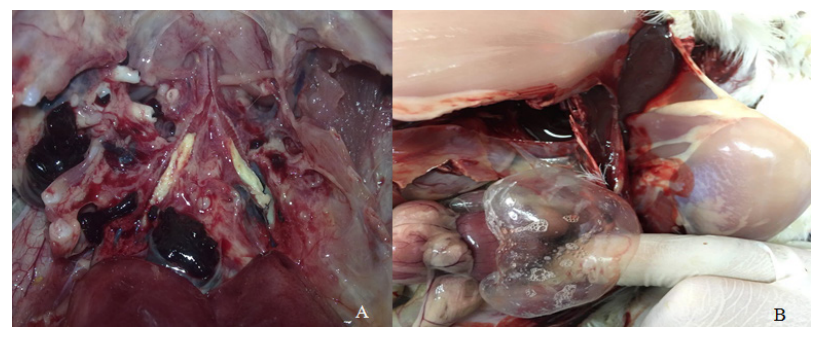

Figure 1. Cast formation at the tracheal bifurcation of challenged birds (A). Slight cloudiness and foamy content of air sac membrane (B).
(PC + treatments groups) groups in all sampling times. The most severe lesions were observed on day 9 PI (Table 3). In the tracheas (PAS staining), significant goblet cell hyperplasia of surface epithelial cells was observed in all treatment groups on days 3 and 6 PI compared to $\mathrm{PC}$ and NC groups $(P<0.01)$ (Figure 2$)$. No significant differences were observed in this parameter among treatment groups (Figure 3).

\section{Ciliostasis}

Although ciliostasis was observed in tracheal samples of birds in all challenged groups, statistically significant differences in the ciliary activity among challenged groups,

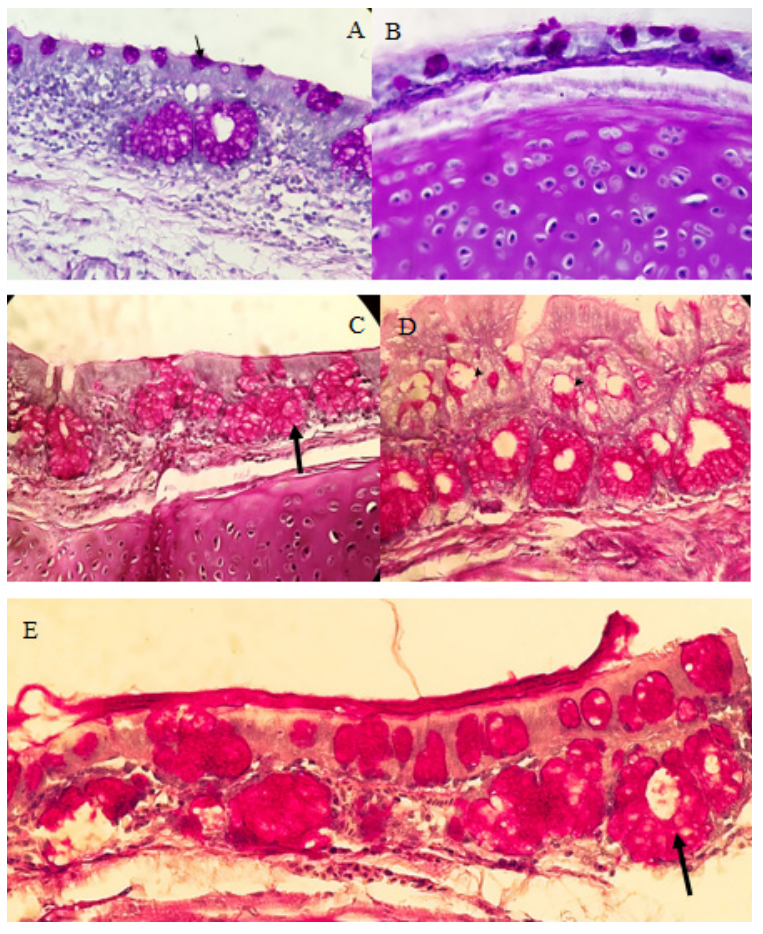

Figure 2. Tracheal goblet cell changes in broiler chickens of different groups on day 6 post challenge with AIV-H9N2 and IB viruses (PAS staining; magnified 40x). Marked goblet cells and goblet glands hyperplasia as well as degeneration of goblet cells are observed in treatment groups. (A): Positive control [Goblet cells (arrow)], (B): Negative control, (C): Mentofin ${ }^{\circledR}$ [Goblet glands (arrow)], (D): bromhexine $1 \%+$ menthol [Degeneration of goblet cells (arrowhead)], (E): Aromax ${ }^{\circledR}$ [Goblet glands (arrow)].

Table 3. Histopahological results in different groups of the experiment

\begin{tabular}{|c|c|c|c|c|c|}
\hline \multirow{3}{*}{ Groups } & \multicolumn{5}{|c|}{ Histopathology score* (Mean \pm SD) } \\
\hline & \multicolumn{5}{|c|}{ Days post infection } \\
\hline & 1 & 3 & 6 & 9 & 12 \\
\hline NC & $1.1 \pm 0.18^{\mathrm{a}}$ & $1.13 \pm 0.18^{\mathrm{a}}$ & $1.13 \pm 0.18^{\mathrm{a}}$ & $1 \pm 0^{\mathrm{a}}$ & $1 \pm 0^{\mathrm{a}}$ \\
\hline PC & $1.1 \pm 0.18^{\mathrm{a}}$ & $2.4 \pm 0.433^{\mathrm{a}}$ & $3.13 \pm 0.56^{b}$ & $3.73 \pm 0.28^{b}$ & $2.73 \pm 0.639^{b}$ \\
\hline G1 & $1.1 \pm 0.18^{\mathrm{a}}$ & $2.6 \pm 0.595^{\mathrm{a}}$ & $2.9 \pm 0.28^{b}$ & $3.45 \pm 0.445^{b}$ & $2.73 \pm 0.547^{b}$ \\
\hline G2 & $1.1 \pm 0.18^{\mathrm{a}}$ & $2.4 \pm 0.719^{\mathrm{a}}$ & $2.65 \pm 0.665^{b}$ & $3.4 \pm 0.433^{b}$ & $2.6 \pm 0.59^{b}$ \\
\hline G3 & $1.1 \pm 0.18^{\mathrm{a}}$ & $2.6 \pm 0.703^{\mathrm{a}}$ & $2.7 \pm 0.868^{b}$ & $3.73 \pm 0.434^{b}$ & $2.8 \pm 0.505^{b}$ \\
\hline
\end{tabular}

${ }^{*}$ The histopathology score was based on epithelial hyperplasia, lymphocyte infiltration, and epithelial deciliation with 1 being normal and 4 being severe. Groups: NC: Negative control, PC: Positive control, G1: Mentofin ${ }^{\circledR}$, G2: Aromax $^{\circledR}$, G3: Bromhexine $1 \%+$ menthol. Different superscript letters in a column indicates significant difference $(P<0.05)$. SD: Standard deviation. 

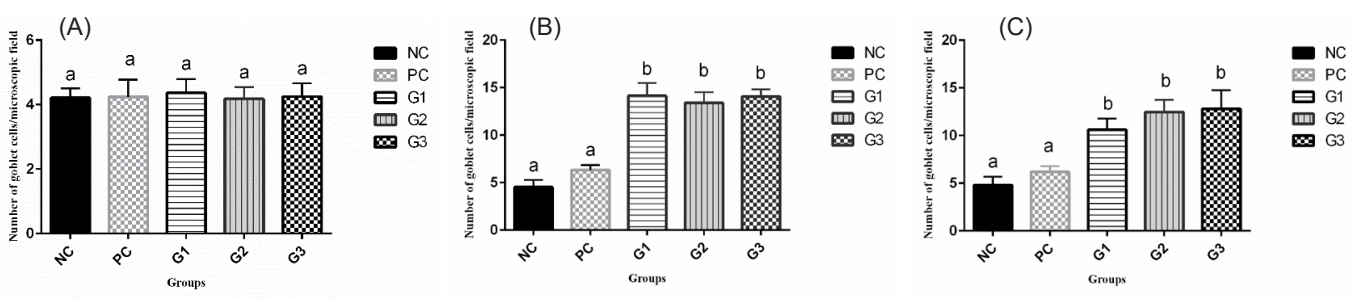

Figure 3. Number of goblet cells per microscopic field (mean \pm SD) in tracheal epithelial surface of birds in different groups on day 1 (A), 3 (B) and 6 (C) post infection. Groups: NC: Negative control, PC: Positive control, G1: Mentofin ${ }^{\circledR}, \mathrm{G} 2$ : Aromax ${ }^{\circledR}$, G3: Bromhexine $1 \%+$ menthol. Different letters indicate significant differences among groups. Error bars indicate the standard deviation (SD).

even among treated birds and PC, were not detected in different sampling days (Table 4).

\section{Discussion}

Symptom relieving agents are widely used in most of the poultry respiratory infections regardless of etiology (viral or bacterial) with little evidence of effectiveness. Many of these drugs are combined products of different herbal derived aromatic volatile substances such as menthol, thymol, eucalyptol and cineol. Menthol has especially attracted much interest in poultry industry and diverse commercial respiratory symptom relieving compounds containing menthol are promoted for use in respiratory infections. However, the exact clinical effectiveness of using these drugs in birds is still debated. In this study, the effects of administration of three available menthol containing medicines on clinical severity and some histopathological aspects were evaluated in broilers infected with H9N2 and IB viruses.

As our first finding, clinical manifestation of H9N2AIV/IBV infection was limited to respiratory signs in all challenged groups regardless of treatment. Mild to moderate clinical signs prolonged to day 9 post challenge. Similar clinical signs were previously reported in mixed H9N2-AI/IBV infection of broilers $(24,25)$. The clinical signs and gross lesions resulting from the dual infection in PC group are similar to but generally milder than

Table 4. Ciliary activity in tracheal rings of chickens in different groups after challenge with H9N2 \& IB viruses

\begin{tabular}{cccc}
\hline \multicolumn{4}{c}{ Ciliary activity score* (Mean \pm SD) $^{\text {DPI }}$} \\
\hline \multirow{2}{*}{ Treatment groups } & \multicolumn{3}{c}{$\mathbf{3}$} \\
\cline { 2 - 4 } & $\mathbf{1}$ & $0^{\mathrm{a}}$ & 6 \\
\hline NC & 0 & $2.14 \pm 0.297^{\mathrm{b}}$ & $2.36 \pm 0.167^{\mathrm{b}}$ \\
\hline PC & 0 & $2.24 \pm 0.251^{\mathrm{b}}$ & $2.5 \pm 0.1000^{\mathrm{b}}$ \\
\hline G1 & 0 & $2.14 \pm 0.0194^{\mathrm{b}}$ & $2.4 \pm 0.141^{\mathrm{b}}$ \\
\hline G2 & 0 & $2.1 \pm 0.223^{\mathrm{b}}$ & $2.4 \pm 0^{\mathrm{b}}$ \\
\hline G3 & 0 &
\end{tabular}

${ }^{*}$ The ciliary movement scored on scale from 0 (100\% ciliary activity) to 4 (total ciliostasis). Groups: NC: Negative control, PC: Positive control, $\mathrm{G} 1$ : Mentofin ${ }^{\circledR}, \mathrm{G} 2$ : Aromax $^{\circledR}, \mathrm{G} 3$ : Bromhexine $1 \%+$ menthol. Different letters in each column indicate significant differences between groups tested at the same time point post infection; SD: standard deviation. those seen in field cases. Moreover, the mortality rate in PC group was only $8.6 \%$ while higher mortality rate has been reported in field conditions $(4,26,27)$. This difference can be attributed to inadequate management and environmental conditions (poor ventilation, high density, high ammonia levels and too low or high relative humidity) and additional pathogens encountered in the field, exacerbating any disease which has been brought about.

Contrary to expectation, treatment with herbal drugs or mucolytic agent not only did not decrease the severity of clinical signs or gross pathological lesions in challengedtreated birds (G1-G3) but also increased the mortality rate in these groups which was similar to those reported by Faghihzadeh et al who reported high mortality in experimentally infected $(\mathrm{H} 9 \mathrm{~N} 2+\mathrm{IBV}+E$. coli) broilers given Bronchimax ${ }^{\circledR}$ or bromhexine compare to PC group (25). These data do not agree with other workers (11) who reported that Mentofin ${ }^{\circledR}$ treatment reduced the mortality in challenged $(\mathrm{H} 9 \mathrm{~N} 2 \mathrm{AIV}+\mathrm{IBV}+\mathrm{MG})$ and unchallenged broilers.

Treatment with herbal compounds had no effect on body weight and FCR in challenged chickens. Consistently in a study reported by Rehman et al. (2013), Mentofin ${ }^{\circledR}$ did not show any effect on FCR and weight gain of treated broilers vaccinated with Newcastle disease vaccine (14). In contrast, Sultan et al demonstrated better performance (lower FCR and higher body weight) in H9N2 infected broilers treated with intermittent administration of Mentofin $^{\circledR}$ (28).

As it was mentioned in the result section, gross lesions in euthanized birds of challenged groups were also limited to respiratory system with no significant differences among groups. Tracheal exudates, airsacculitis, tracheal congestion as well as bronchial casts/plugs formation mostly extended to the lower bronchi were the main lesions observed in mixed infection of H9N2 -AI and IB viruses in dead birds of challenged groups which were in accordance with previous reports $(24,25)$. According to necropsy findings in dead birds of all challenged groups, it seems that mucoid or fibrinonecrotic cast/plug formation especially in tracheal bifurcation which is observed in mixed infection of H9N2/IB viruses $(24,26,29)$ is the main cause for partial to complete blockage of trachea, 
asphyxiation and mortality of chickens especially in treated groups. Although it has been postulated that the tracheal casts/plugs are formed due to mucus hypersecretion and may cause death in single AIV/H9N2 and mixed AIVH9N2/IBV infections (24) or even in co-infections with other bacterial agents (30), there is no published report to clarify the mechanism behind cast/plug formation. Thus, we evaluated ciliary activity and histopathological changes (using H\&E stain) of trachea with emphasis on changes in tracheal epithelial goblet cell number (using PAS stain) leading to mucus hypersecretion in H9N2/IBV infected broilers as well as infected-treated broilers, which received different herbal drugs.

Based on microscopic lesions in $\mathrm{H} \& \mathrm{E}$ stained sections, congestion of trachea with deciliation of tracheal epithelial cells, epithelial hyperplasia and lymphocyte infiltration into the mucosa of trachea are the predominant lesions observed in all challenged groups (with no significant differences among groups) which may explain the formation of plug/cast in trachea (26). In contrast, Mentofin ${ }^{\circledR}$ reduced deciliation and heterophil infiltration, which normally is caused by H9N2-AIV and MG (11).

Although the number of goblet cells increased in tracheal epithelium of birds in PC group, these differences were not significant compared to NC group. An interesting observation of the current study was goblet cell hyperplasia in the airway epithelium of challenged-treated groups. Treatment with herbal agents induced an increase of more than twofold in the number of goblet cells compared with the PC group, while they did not significantly influence on tracheal deciliation or lymphocytes infiltration. Contrary to our results, it has been reported that Mentofin ${ }^{\circledR}$ significantly decreases tracheal deciliation, mucosal hypertrophy and tracheal goblet cells degeneration in MG/AIV-H9N2 challenged broiler chickens compared to inoculated birds deprived from this treatment (11). The reason behind this controversy may be due to differences of the causative agent of the infection (MG versus IBV).

Our finding reveals that the administration of different herbal preparations adversely affects the tracheal epithelium via enhancement of goblet cell hyperplasia. While increase in the number of goblet cells or mucin production are essential for clearing infections, hypersecretion and accumulation of mucus in conjunction with default in ciliary activity causes airway narrowing and therefore contributes to tracheal or bronchial obstruction. Menthol is known to have inhibitory effect on mucociliary transport system. It has been reported that menthol increases mucus production in the airways of mammals, which may not always be beneficial $(31,32)$. Mucociliary system acts as a non-specific defense mechanism against respiratory pathogens. Mucus which coats the respiratory tract mucosal surface serves as a protective layer and the ciliary motility can clear the substances from the tracheal mucosa (33). Ciliostasis was observed in all challenged groups of this study regardless of treatment.

Administration of bromhexine $1 \%+$ menthol caused higher death (28.6\%) compared to G1 and G3 groups. Rheological study of tracheobronchial secretions of chicken treated with various mucolytic drugs revealed that cilia from healthy birds medicated with bromhexine, required greater force to displace mucus compared to untreated birds (34). According to this fact, decreasing mucus motion following mucolytic activity of bromhexine may be involved in worsening severity of the clinical manifestation of the disease in the chickens of group G3.

\section{Conclusion}

Overall, our results indicated that use of herbal medications, which is very common in the symptomatic treatment of respiratory disease in poultry industry, aggravates mortality and deteriorates the conditions and should be used cautiously and after proper clinical judgement. It appears that hyper-secretion of mucosa along with ciliary incompetence causes mucus stagnation followed by tracheal or bronchial obstruction and death. These findings necessitate cautious use of these products. Nevertheless, further work is required.

\section{Acknowledgements}

We thank Iran Veterinary Organization, Fars branch, for the support of this project. Authors are grateful to Ms. Mitra Mohammadi, Staff of the Department of Clinical Sciences, School of Veterinary Medicine, Shiraz University, Shiraz, Iran for her kind help in virus propagation.

\section{Authors' contributions}

$\mathrm{DH}$ and $\mathrm{MN}$ had major roles in hypothesis making, preparation of the manuscript and data interpretation. AM committed data acquisition and sampling. BZ and RG had major roles in running experiments. All authors have read and approved the manuscript.

\section{Conflict of interests}

All authors declare that no conflict of interest exist.

\section{Ethical considerations}

This study was carried out in accordance with ethical guidelines of the Institutional Animal Care and Use Committee, which set by the European convention (No.123; Appendix A). The project was confirmed by the ethical committee of Shiraz University (Code number: 95GCU2M163723).

\section{Funding/Support}

This study was partially funded by Iran Veterinary Organization, Fars branch. Funding for this study was also provided by Shiraz University according to grant number 95GCU2M163723. 


\section{References}

1. Peacock THP, James J, Sealy JE, Iqbal M. A global perspective on H9N2 avian influenza virus. Viruses. 2019;11(7). doi: 10.3390/v11070620.

2. Kammon A, Heidari A, Dayhum A, Eldaghayes I, Sharif $\mathrm{M}$, Monne I, et al. Characterization of avian influenza and Newcastle disease viruses from poultry in Libya. Avian Dis. 2015;59(3):422-30. doi: 10.1637/11068-032215-ResNote.1.

3. Jackwood MW. Review of infectious bronchitis virus around the world. Avian Dis. 2012;56(4):634-41. doi: 10.1637/10227-043012-Review.1.

4. Hassan KE, Shany SA, Ali A, Dahshan AH, El-Sawah AA, El-Kady MF. Prevalence of avian respiratory viruses in broiler flocks in Egypt. Poult Sci. 2016;95(6):1271-80. doi: 10.3382/ps/pew068.

5. Seifi S, Asasi K, Mohammadi A. Natural co-infection caused by avian influenza H9 subtype and infectious bronchitis viruses in broiler chicken farms. Veterinarski Arh. 2010;80(2):269-81.

6. Karimi-Madab M, Ansari-Lari M, Asasi K, Nili H. Risk factors for detection of bronchial casts, most frequently seen in endemic H9N2 avian influenza infection, in poultry flocks in Iran. Prev Vet Med. 2010;95(3-4):275-80. doi: 10.1016/j.prevetmed.2010.03.010.

7. Schnitzler P, Koch C, Reichling J. Susceptibility of drugresistant clinical herpes simplex virus type 1 strains to essential oils of ginger, thyme, hyssop, and sandalwood. Antimicrob Agents Chem other. 2007;51(5):1859-62. doi: 10.1128/aac.00426-06.

8. Koch C, Reichling J, Kehm R, Sharaf MM, Zentgraf $\mathrm{H}$, Schneele J, et al. Efficacy of anise oil, dwarf-pine oil and chamomile oil against thymidine-kinasepositive and thymidine-kinase-negative herpesviruses. J Pharm Pharmacol. 2008;60(11):1545-50. doi: 10.1211/ jpp/60.11.0017.

9. Bassolé IH, Juliani HR. Essential oils in combination and their antimicrobial properties. Molecules. 2012;17(4):39894006. doi: 10.3390/molecules 17043989.

10. Krishan G, Narang A. Use of essential oils in poultry nutrition: a new approach. J Adv Vet Anim Res. 2014;1(4):156-62. doi: 10.5455/javar.2014.a36.

11. Barbour EK, El-Hakim RG, Kaadi MS, Shaib HA, Gerges DD, Nehme PA. Evaluation of the histopathology of the respiratory system in essential oil-treated broilers following a challenge with Mycoplasma gallisepticum and/or H9N2 Influenza virus. Int J Appl Res Vet Med. 2006;4(4):293-300.

12. Barbour EK, Saadé MF, Abdel Nour AM, Kayali G, Kidess S, Bou Ghannam R, et al. Evaluation of essential oils in the treatment of broilers co-infected with multiple respiratory etiologic agents. Int J Appl Res Vet Med. 2011;9(4):317-23.

13. Shayeganmehr A, Vasfi Marandi M, Karimi V, Barin A, Ghalyanchilangeroudi A. Zataria multiflora essential oil reduces replication rate of avian influenza virus (H9N2 subtype) in challenged broiler chicks. $\mathrm{Br}$ Poult Sci. 2018;59(4):389-95. doi: 10.1080/00071668.2018.1478064.

14. Rehman SR, Muhammad K, Yaqub T, Khan MS, Hanif K, Yasmeen R. Antimicrobial activity of mentofin and its effect on antibody response of broilers to Newcastle disease virus vaccine. J Anim Plant Sci. 2013;23(4):1008-11.

15. Kahaya S, Önat K, Erköse E, Temelli S, Eyigor A, Carli
KT. Effect of Mentofin application on the clearance of Mycoplasma gallisepticum (MG) from naturally infected layer chickens'trachea. Ankara Univ Vet Fak Derg. 2015;62(1):17-21. doi: 10.1501/vetfak_0000002652.

16. Awaad MHH, Abdel-Alim GA, Sayed KSS, Ahmed A, Nada AA, Metwalli ASZ, et al. Immunostimulant effects of essential oils of peppermint and eucalyptus in chickens. Pak Vet J. 2010;30(2):61-6.

17. Thajel F, Ulaiwi AH. Effect of AROMAX ${ }^{\circledR}$ on performance, local and humoral immunity against vaccination of Newcastal disease in the low management level in broiler chicken. J Entomol Zool Stud. 2017;5(5):1986-90.

18. Shah MU, Aslam A, Mustafa G, Zahid B, Imran MS. Effect of Mentofin and ASI-MIRUS on humoral immune response and tissue changes in infectious bursal disease vaccinated broiler birds. Pak Vet J. 2018;38(1):56-60.

19. Vriens J, Nilius B, Vennekens R. Herbal compounds and toxins modulating TRP channels. Curr Neuropharmacol. 2008;6(1):79-96. doi: 10.2174/157015908783769644.

20. Zanasi A, Mazzolini M, Kantar A. A reappraisal of the mucoactive activity and clinical efficacy of bromhexine. Multidiscip Respir Med. 2017;12:7. doi: 10.1186/s40248017-0088-1.

21. Reed LJ, Muench H. A simple method of estimating fifty per cent endpoints. Am J Epidemiol. 1938;27(3):493-7. doi: 10.1093/oxfordjournals.aje.a118408.

22. Jackwood MW, Rosenbloom R, Petteruti M, Hilt DA, McCall AW, Williams SM. Avian coronavirus infectious bronchitis virus susceptibility to botanical oleoresins and essential oils in vitro and in vivo. Virus Res. 2010;149(1):8694. doi: 10.1016/j.virusres.2010.01.006.

23. Darbyshire JH. Assessment of cross-immunity dm chickens to strains of avian infectious bronchitis virus using tracheal organ cultures. Avian Pathol. 1980;9(2):179-84. doi: 10.1080/03079458008418401.

24. Hassan KE, Ali A, Shany SAS, El-Kady MF. Experimental co-infection of infectious bronchitis and low pathogenic avian influenza H9N2 viruses in commercial broiler chickens. Res Vet Sci. 2017;115:356-62. doi: 10.1016/j. rvsc.2017.06.024.

25. Faghihzadeh S, Asasi K, Abdi-Hachesoo B. Effects of relative humidity and commercial medicinal treatments on complex respiratory infections and pathology in broilers. Online J Vet Res. 2018;22(2):139-49.

26. Nili H, Asasi K. Natural cases and an experimental study of H9N2 avian influenza in commercial broiler chickens of Iran. Avian Pathol. 2002;31(3):247-52. doi: 10.1080/03079450220136567.

27. Nili H, Asasi K. Avian influenza (H9N2) outbreak in Iran. Avian Dis. 2003;47(3 Suppl):828-31. doi: 10.1637/00052086-47.s3.828.

28. Sultan R, Aslam A, Saleem G, Anjum A, Krull W, Kumosani $\mathrm{T}$, et al. Studies on performance, immunity, and safety of broilers vaccinated with killed H9N2 vaccine and supplemented with essential oils of Mentofin ${ }^{\circledR}$ in drinking water. Int J Appl Res Vet Med. 2017;15(2):67-74.

29. Perk S, Banet-Noach C, Shihmanter E, Pokamunski S, Pirak M, Lipkind M, et al. Genetic characterization of the H9N2 influenza viruses circulated in the poultry population in Israel. Comp Immunol Microbiol Infect Dis. 
2006;29(4):207-23. doi: 10.1016/j.cimid.2006.06.004.

30. Dwars RM, Matthijs MG, Daemen AJ, van Eck JH, Vervelde L, Landman WJ. Progression of lesions in the respiratory tract of broilers after single infection with Escherichia coli compared to superinfection with E. coli after infection with infectious bronchitis virus. Vet Immunol Immunopathol. 2009;127(1-2):65-76. doi: 10.1016/j.vetimm.2008.09.019.

31. Gavliakova S, Buday T, Manjunath Shetthalli V, Plevkova J. Analysis of pathomechanisms involved in side effects of menthol treatment in respiratory diseases. Open J Mol Integr Physiol. 2013;3(1):27863. doi: 10.4236/ojmip.2013.31004.

32. Abanses JC, Arima S, Rubin BK. Vicks VapoRub induces mucin secretion, decreases ciliary beat frequency, and increases tracheal mucus transport in the ferret trachea. Chest. 2009;135(1):143-8. doi: 10.1378/chest.08-0095.

33. Bustamante-Marin XM, Ostrowski LE. Cilia and mucociliary clearance. Cold Spring Harb Perspect Biol. 2017;9(4). doi: 10.1101/cshperspect.a028241.

34. Carrillo L, Sumano H, Medina-Torres L, Tapia G, Gutiérrez L. Rheological study of healthy chicken's pooled tracheobronchial secretions and its modification by mucolytics drugs. Poult Sci. 2016;95(11):2667-72. doi: $10.3382 /$ ps/pew209. 